\title{
Impact of weight loss on markers of systemic inflammation in obese Saudi children with asthma
}

\author{
*Abd El- Kader MS ${ }^{1}$, Al-Jiffri $\mathrm{O}^{2}$, Ashmawy EM ${ }^{1}$
}

\author{
1. Department of Physical therapy, Faculty of Applied Medical Sciences, King Abdulaziz University, Saudi \\ Arabia. \\ 2. Department of Medical Laboratory Technology, Faculty of Applied Medical Sciences, King Abdulaziz \\ University, Saudi Arabia.
}

\begin{abstract}
Background: Weight loss studies were conducted in children without asthma have demonstrated a reduction in systemic inflammation. However, the impact of weight loss in the obese paediatric population with asthma has not been investigated. Objective: To measure the effects of weight loss on markers of systemic inflammation in obese children with bronchial asthma.

Methods: Eighty obese children with bronchial asthma (42 boys, and 38 girls) with mean age $13.86 \pm 3.21$ years were divided into two equal groups. The training group received diet regimen, exercise training in addition to the medical treatment for two months, where the control group received the medical treatment only.

Results: There was a $17.5 \%, 15.5 \%, 22.4 \%, 14.1 \%$ and $15.9 \%$ reduction in mean values of tumor necrosis factor-alpha (TNF-alpha), interleukin-6 (IL-6), interleukin-8 (IL-8), Leptin and body mass index (BMI) respectively and $38.7 \%$ increase in mean values of adiponectin in the training group. While, there was a $0.7 \%, 9.0 \%, 2.8 \%, 1.6 \%$ and $1.2 \%$ increase in mean values of TNF-alpha, IL-6, IL-8, Leptin and BMI respectively and 3.9\% decrease in mean values of adiponectin in the control group. The mean values of TNF-alpha, IL-6, IL-8, Leptin and BMI was decreased and adiponectin was increased significantly in the training group, however the results of the control group were not significant. Also, there were significant differences between both groups at the end of the study.

Conclusion: Weight loss improves markers of systemic inflammation in obese Saudi children with bronchial asthma.

Key words: obesity, asthma, weight loss, cytokines.

African Health Sciences 2013; 13(3): 682 - 688 http://dx.doi.org/10.4314/ahs.v13i3.23
\end{abstract}

\section{Introduction}

Over the last few decades, the prevalence of Asthma and obesity are has increased worldwide and received the major public health concerns. In the United States the prevalence of overweight status increased from $6.5 \%$ to approximately $19 \%$ in school-aged children between 1976-1980 and 2003-2004 ${ }^{1}$. The mechanisms and consequences of the observed association between obesity and childhood asthma are unclear ${ }^{2}$.

There is increasing evidence of shared genetic determinants of asthma and obesity. The genes for the â2-adrenergic and glucocorticoid

$$
\begin{aligned}
& \text { *Corresponding author: } \\
& \text { Prof. Shehab M. Abd El- Kader } \\
& \text { Department of Physical Therapy } \\
& \text { Faculty of Applied Medical Sciences } \\
& \text { King Abdulaziz University } \\
& \text { P.O. Box 80324 } \\
& \text { Jeddah, 21589, Saudi Arabia. } \\
& \text { Phone: +966-569849276 } \\
& \text { E. mail: salmuzain@kau.edu.sa }
\end{aligned}
$$

receptors are located on chromosome $5 \mathrm{q}$ and have been implicated in pathways related to both asthma and obesity ${ }^{3,4}$. So the prevalence of asthma in children has paralleled the rise in obesity; obesity may increase the severity of asthma ${ }^{5}$. Asthma and obesity have serious health consequences and significant financial costs. Excess body weight is also associated with an increase in the number of school days missed by asthmatic children and significantly reduced quality of life ${ }^{6}$.

Adipose tissue communicates with other organs through endocrine capabilities, releasing important mediators produced by tissue-resident macrophages and adipocytes, including tumour necrosis factor-alpha (TNF-alpha), interleukins, leptin and adiponectin. Obesity creates a proinflammatory environment via an increase in adipocyte volume and number and production of inflammatory mediators. The presence of excess adiposity therefore provides a consistent stimulus for chronic, low grade systemic inflammation ${ }^{7,8}$. 
There also is evidence of a generalized proinflammatory state in obesity, with levels of several cytokines and chemokines increased in obese subjects 9. TNF-alpha haplotypes have been associated with asthma and airway hyperresponsiveness ${ }^{10}$ and with obesity ${ }^{11}$. TNF-alpha and IL- 6 are produced by adipocytes and correlate with total body fat ${ }^{12}$ and TNF-alpha increases production of IL-6 in both obesity and asthma ${ }^{13}$.

Adipocytes secrete a number of substances that might influence airway inflammation and reactivity. Shore et al have shown that leptin can increase IgE levels and airway responsiveness after allergen exposure in murine models ${ }^{14}$. Adiponectin is the only adipokine reduced in obesity, and it has been shown that exogenous adiponectin reduces or abolishes airway inflammation and responsiveness in mice exposed to inhaled allergens ${ }^{15}$. Also, Kattan et al reported that adiponectin was associated with increasing FEV1/FVC ratios and decreasing asthma symptoms and exacerbations in asthmatic teenage male subjects ${ }^{16}$.

A growing body of literature implicates decreased physical activity as a contributor to the increase of asthma prevalence ${ }^{17}$. Obesity leads to increased asthma symptoms and worsening disease, which itself can be associated with less physical activity. Less physical activity, in turn, predisposes a patient to obesity and long-term respiratory problems, thereby sustaining the vicious cycle of inactivity, obesity, and worsening asthma. Lucas and Platts-Mills found that asthmatic children have a lower aerobic fitness level than their non-asthmatic peers, citing a complex inter-relationship between asthma, obesity, and inactivity ${ }^{18}$. The obese asthma phenotype can be reversed by weight loss with improvements in lung function, asthma control and asthma severity with decreased medication utilization and hospitalizations ${ }^{19,20}$.

This study was an attempt to measure the effects of weight loss on markers of systemic inflammation in obese children with bronchial asthma.

\section{Methods}

\section{Subjects}

Eighty obese Saudi children with bronchial asthma (42 boys, and 38 girls), their age ranged $12-18$ years, their body mass index (BMI) ranged $30-35 \mathrm{~kg} / \mathrm{m}^{2}$ were selected from pediatric Department, King Abdulaziz University Teaching Hospital, Saudi Arabia. Children participated in this study were randomly divided into two equal groups (The training and the control groups). The training group received diet regimen, exercise training and medical treatment where the control group received only medical treatment. Cardiac, diabetic and patients with chest disease rather than bronchial asthma were excluded from the study. Informed consent was obtained from parents of all participants. This study was approved by the Scientific Research Ethical Committee, Faculty of Applied Medical Sciences at King Abdulaziz University. Informed consent was obtained from parents of all participants who were free to withdraw from the study at any time. If any adverse effects had occurred, the experiment will be terminated and the Human Subjects Review Board will be informed.

\section{Evaluated parameters \\ Laboratory measurements}

While all the subjects were fasten; $10 \mathrm{cc}$ of blood was taken from their brachial vein, all blood sampling were done from 8a.m to 9a.m. Also, 48 hours after finishing the 8 -weeks exercise program, post-testing blood sampling was done under the same conditions. All the samples were rapidly put in EDTA-containing tubes and kept in the refrigerator until they were centrifuged. Centrifuge was done at the gravity of 3000 , temperature of $-4^{\circ} \mathrm{C}$, for 15 minutes, and the separated plasma was kept at the temperature of $-80^{\circ} \mathrm{C}$. Plasma leptin, adiponectin and resistin, were measured using ELISA kits (Mediagnost, Reuttlinger, Germany) for leptin plasma tumor necrosis factor-alpha (TNF-alpha), interleukin-6 (IL6), interleukin-8(IL-8) and (Adipogen co., South Korea) for adiponectin.

\section{Evaluation of anthropometric parameters}

For all participants their height was measured with a digital stadiometer to the nearest $0.1 \mathrm{~cm}$ (JENIX DS 102, Dongsang, South Korea). Body weight was measured on a calibrated balance scale to the nearest $0.1 \mathrm{~kg}$ (HC4211, Cas Korea, South Korea), and body mass index (BMI) was calculated as Body weight/ Height $^{2}$. Measurements of leptin, adiponectin, TNFalpha, IL-6, IL-8 and BMI were done before the study and after two months at the end of the study.

\section{Ventilatory function test}

Spirometer (Schiler- Spirovit SP-10) was used to measure forced vital capacity (FVC) and forced expiratory volume in the first second (FEV1) as FEV1 and FEV1/FVC ratio are widely used in 
clinical practice and constitute one of the components of the "Guidelines for the diagnosis and management of asthma" from the National Heart, Lung, and Blood Institute to assess asthma severity and asthma control and to adjust management ${ }^{21}$.

\section{Controlling nutrition}

The interview-based food survey was performed for all children and their parents by dieticians to specify previous food habits and possible anomalies in dietary behavior. The prescribed low calorie diet was balanced, with $15 \%$ as protein, 30 to $35 \%$ as fat and 50 to $55 \%$ as carbohydrate, on average, in order to provide about $250 \mathrm{kcal}$ per day as Butte and Ellis 90 calculated that an energy deficit of more than $250 \mathrm{kcal}$ per day is needed to prevent further weight gain $^{22}$.

\section{Training program}

The experimental group carried out the aerobic exercises, every other day, four sessions a week, for 8 weeks. These exercises included warm up, main training, and cool down. Subjects warmed up by stretching and jogging for 10 minutes. The main training included basic physical fitness movements (running, jumping and playing with medicine ball) and treadmill-based training program (Enraf Nonium, Model display panel Standard, NR 1475.801, Holland) reaching 60 to $80 \%$ of the maximum heart rate done for 15 minutes in the first session and increasing gradually to be 35 minutes by the end of the eighth week. Cooling down included the static stretching movements. The performance of the subjects was controlled by a physical education expert and their heartbeat was constantly checked by the polar device (POX 1000 Japan), and control group remained sedentary in this period.

\section{Statistical analysis}

The mean values of TNF-alpha, IL-6, IL-8, Leptin, adiponectin and BMI were compared using paired " $t$ " test. Independent " $t$ " test was used for the comparison between the two groups $(\mathrm{P}<0.05)$.

\section{Results}

The two groups were considered homogeneous re-garding the Baseline descriptive characteristics (table 1). There was a 17.5\% , 15.5\%, 22.4\%, 14.1\% and $15.9 \%$ reduction in mean values of tumor necrosis factor-alpha (TNF-alpha), interleukin-6 (IL6), interleukin-8 (IL-8), Leptin and body mass index (BMI) respectively and $38.7 \%$ increase in mean values of adiponectin in the training group (table 2). While, there was a $0.7 \%, 9.0 \%, 2.8 \%, 1.6 \%$ and $1.2 \%$ increase in mean values of TNF-alpha, IL-6, IL-8, Leptin and BMI respectively and 3.9\% decrease in mean values of adiponectin in the control group. The mean values of TNF-alpha, IL-6, IL-8, Leptin and BMI was decreased and adiponectin was increased significantly in the training group, however the results of the control group were not significant (table 3). Also, there were significant differences between both groups at the end of the study (table 4).

\section{Table 1: Baseline descriptive characteristics}

\begin{tabular}{lll}
\hline Variable & Group (A) & Group (B) \\
\hline Age (year) & $13.16 \pm 3.54$ & $12.57 \pm 3.21$ \\
Weight $(\mathrm{Kg})$ & $65.32 \pm 4.17$ & $63.52 \pm 5.48$ \\
Height $(\mathrm{cm})$ & $140.51 \pm 6.23$ & $139.94 \pm 5.76$ \\
FEV $_{1} \%$ pred & $71(58-80)$ & $70(56-78)$ \\
$\mathrm{FVC}_{\text {\% pred }}$ & $88(84-93)$ & $86(82-90)$ \\
$\mathrm{FEV}_{1} / \mathrm{FVC} \%$ & $62(55-70)$ & $60(52-68)$ \\
Maximum symptom & $2.23 \pm 1.15$ & $1.97 \pm 1.28$ \\
days (no. of days/last 2 weeks)
\end{tabular}

$\mathrm{FEV}_{1}=$ forced expiratory volume in the first second

$\mathrm{FVC}=$ Forced vital capacity 
Table 2: Mean value and significance of TNF- alpha IL-6, IL-8, Leptin, Adiponectin and BMI in group (A) before and after treatment

\begin{tabular}{lllll}
\hline & \multicolumn{2}{c}{ Mean + SD } & t- value & Significant \\
\cline { 2 - 3 } & Pre & Post & & \\
\hline TNF-alpha $(\mathrm{pg} / \mathrm{mL})$ & $4.32 \pm 1.54$ & $3.56 \pm 1.12$ & 3.80 & $\mathrm{P}<0.05$ \\
IL-6 $(\mathrm{pg} / \mathrm{mL})$ & $2.19 \pm 0.81$ & $1.85 \pm 0.76$ & 3.64 & $\mathrm{P}<0.05$ \\
IL-8 $(\mathrm{pg} / \mathrm{mL})$ & $15.66 \pm 4.63$ & $12.14 \pm 3.72$ & 4.52 & $\mathrm{P}<0.05$ \\
Leptin Ng/ml & $31.43 \pm 5.47$ & $26.98 \pm 4.50$ & 5.83 & $\mathrm{P}<0.05$ \\
Adiponectin $(\mu \mathrm{g} / \mathrm{mL})$ & $10.61 \pm 3.45$ & $14.72 \pm 3.21$ & 5.11 & $\mathrm{P}<0.05$ \\
BMI $\left(\mathrm{kg} / \mathrm{m}^{2}\right)$ & $32.31 \pm 2.46$ & $27.15 \pm 2.38$ & 4.74 & $\mathrm{P}<0.05$ \\
\hline
\end{tabular}

TNF- alpha $=$ tumor necrosis factor - alpha.

IL-8= Interleukin-8

IL-6 = Interleukin-6

BMI $=$ Body Mass Index

Table 3: Mean value and significance of TNF- alpha, IL-6, IL-8, Leptin, Adiponectin and BMI in group (B) before and after treatment

\begin{tabular}{|c|c|c|c|c|}
\hline & Mean + SD & & t- value & Significant \\
\hline & Pre & Post & & \\
\hline TNF-alpha (pg/mL) & $4.28 \pm 1.63$ & $4.31 \pm 1.41$ & 0.64 & $\mathrm{P}>0.05$ \\
\hline IL-6 $(\mathrm{pg} / \mathrm{mL})$ & $2.11 \pm 0.88$ & $2.30 \pm 0.75$ & 0.75 & $\mathrm{P}>0.05$ \\
\hline IL-8 (pg/mL) & $15.22 \pm 4.24$ & $15.65 \pm 4.11$ & 0.87 & $\mathrm{P}>0.05$ \\
\hline Leptin $\mathrm{Ng} / \mathrm{ml}$ & $30.53 \pm 5.22$ & $31.02 \pm 4.84$ & 1.16 & $\mathrm{P}>0.05$ \\
\hline $\begin{array}{l}\text { Adiponectin } \\
(\mu \mathrm{g} / \mathrm{mL})\end{array}$ & $11.20 \pm 3.17$ & $10.76 \pm 2.85$ & 0.98 & $\mathrm{P}>0.05$ \\
\hline$\underline{\operatorname{BMI}\left(\mathrm{kg} / \mathrm{m}^{2}\right)}$ & $31.73 \pm 2.12$ & $32.14 \pm 2.16$ & 1.14 & $\mathrm{P}>0.05$ \\
\hline
\end{tabular}

Table 4: Mean value and significance of TNF- alpha, IL-6, IL-8, Leptin, Adiponectin and BMI in group (A) and group (B) after treatment

\begin{tabular}{lccll}
\hline & \multicolumn{2}{c}{ Mean + SD } & t- value & Significant \\
\cline { 2 - 3 } & Group (A) & Group (B) & & \\
\hline TNF-alpha $(\mathrm{pg} / \mathrm{mL})$ & $3.56 \pm 1.12$ & $4.31 \pm 1.41$ & 3.96 & $\mathrm{P}<0.05$ \\
IL-6 $(\mathrm{pg} / \mathrm{mL})$ & $1.85 \pm 0.76$ & $2.30 \pm 0.75$ & 3.81 & $\mathrm{P}<0.05$ \\
IL-8 $(\mathrm{pg} / \mathrm{mL})$ & $12.14 \pm 3.72$ & $15.65 \pm 4.11$ & 4.72 & $\mathrm{P}<0.05$ \\
Leptin Ng/ml & $26.98 \pm 4.50$ & $31.02 \pm 4.84$ & 6.13 & $\mathrm{P}<0.05$ \\
Adiponectin $((\mu \mathrm{g} / \mathrm{mL})$ & $14.72 \pm 3.21$ & $10.76 \pm 2.85$ & 5.26 & $\mathrm{P}<0.05$ \\
BMI $\left(\mathrm{kg} / \mathrm{m}^{2}\right)$ & $27.15 \pm 2.38$ & $32.14 \pm 2.16$ & 4.55 & $\mathrm{P}<0.05$ \\
\hline
\end{tabular}

TNF- alpha $=$ tumor necrosis factor - alpha.

IL-6 = Interleukin-6

IL-8= Interleukin-8

$\mathrm{BMI}=$ Body Mass Index

\section{Discussion}

It is well-documented in the literature that both asthma and obesity are inflammatory diseases ${ }^{23}$. Reported observations suggest that obesity might impact the lung in multiple ways, both extrinsically by excessive body fat that restricts breathing pattern and intrinsically through an inflammatory process ${ }^{24}$. This pro-inflammatory state is theorized to lead to production of inflammatory cytokines, can cause airway inflammation, alter lung development or physiology, and may lead to asthma ${ }^{25}$. The results of the present study showed that plasma leptin, IL6, IL- 8 and BMI have been decreased after 8 weeks of aerobic exercises and diet regimen and as result weight loss. This change in the level of leptin has been reported by a great range of previous studies ${ }^{26}$, $27,28,29$. 
The level of leptin in the blood has reduced after 2 weeks of skiing exercises in a group of $\operatorname{men}^{26}$. The leptin level in a group of old men (65-75 years) divided into three groups of light, moderate and heavy training was decreased after a year of resistance training. Fat percentage and BMI decreased in the three experimental groups and this decrease was more at heavier intensities. The changes in the level of leptin and BMI are in agreement with the results of this study ${ }^{27}$. Even modest dietary alterations can result in decreased markers of oxidative stress and inflammation in overweight patients with moderate asthma ${ }^{28}$.Also, significant reductions in BMI, fat mass, IL-6, IL-8 and leptin concentrations was achieved after only 3 wks following a diet and physical activity intervention ${ }^{29}$.

Current study showed that the plasma adiponectin increases following 8 weeks of aerobic training. The changes in the level of adiponectin because of adaptation with the aerobic exercises in most of the previous studies have shown the same

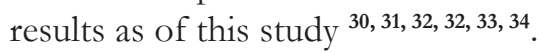

In a study on young and middle-aged women, doing ten weeks of aerobic training resulted in an increase in the plasma levels of adiponectin alongside with a decrease in insulin resistance ${ }^{30}$. Also, eight young fat women $(B M I>25)$ showed a significant decrease in the level of fat mass and leptin, also an increase in the level of adiponectin after 7 months of aerobic training program ${ }^{31}$.

Bruun et al. reported that very obese subjects (mean BMI $=45.8$ ), after executing a program of 15 weeks of aerobic training and a low-calorie diet, showed significant increases in the plasma levels of CRP, IL6 and adiponectin. It can be concluded that diets have a prominent impact on creating increased levels of adiponectin due to exercising ${ }^{32}$. While Esposito and colleagues who reported that weight loss in obese women resulted in significant decreases in previously elevated IL-6, IL-8 in addition to a significant increase in the anti-inflammatory adipokine and adiponectin ${ }^{33}$. Also, Reinher etal, proved that weight loss was accompanied by a $15 \%$ increase in adiponectin and 19\% reduction in leptin ${ }^{34}$.

In another study, nine overweight children performed a progressive aerobic program for 8 weeks. The results showed that none of the adipokines (adiponectin, leptin, resistin, interleukine 6, TNF alpha and CRP) changed significantly. Researchers announced that the reason for this result is probably the lack of weight loss and that exercising does not directly affect the hormones ${ }^{35}$.

\section{Conclusion}

Weight loss improves markers of markers of systemic inflammation in obese Saudi children with bronchial asthma, so it is recommended to apply a weight reduction program to modulate inflammatory cytokines in obese asthmatic children.

\section{Acknowledgment}

This project was funded by the Deanship of Scientific Research (DSR), King Abdulaziz University, Jeddah, under grant no. (46/142-1432). The authors, therefore, acknowledge with thanks DSR technical and financial support.

\section{References}

1. Patel SP, Jarvelin MR, Little MP. Systematic review of worldwide variations of the prevalence of wheezing symptoms in children. Environ Health 2008; 7: 57.

2. Forno E., Lescher R., Strunk R., Weiss S., Fuhlbrigge A., Celedón JC. Decreased response to inhaled steroids in overweight and obese asthmatic children. Journal of Allergy and Clinical Immunology 2011; 127, (3):741-749.

3. Ma J, Xiao L, Knowles S. Obesity, insulin resistance and the prevalence of atopy and asthma in US adults. Allergy 2010; 65: 1455-1463

4. Hawkins GA, Amelung PJ, Smith RS, Jongepier H, Howard TD, Koppelman GH, et al. Identification of polymorphisms in the human glucocorticoid receptor gene (NR3C1) in a multiracial asthma case and control screening panel. DNA Seq 2004; 15: 167-173.

5. Fiorino E, Brooks L. Obesity and respiratory diseases in childhood. Clin Chest Med. 2009; 30/ 3:601-8.

6. van Gent R, van der Ent C, Rovers M, Kimpen J, van Essen-Zandvliet L, de Meer G. Excessive body weight is associated with additional loss of quality of life in children with asthma. $J$ Allergy Clin Immunol. 2007; 119: 591-596.

7. Kershaw E., Flier J. Adipose Tissue as an Endocrine Organ. J Clin Endocrinol Metab 2004; 89: 2548-2556.

8. Fantuzzi G. Adipose tissue adipokines, and inflammation .J Allergy Clin Immunol 2005; 115: 911-919.

9. Warnberg J, Marcos A. Low-grade inflammation and the metabolic syndrome in children and adolescents. Curr Opin Lipidol 2008; 19: 11-15. 
10. Choi IW, Sun K., Kim YS, Ko HM, Im SY, $\mathrm{Kim} J \mathrm{H}$, et al. TNF-alpha induces the late-phase airway hyperresponsiveness and airway inflammation through cytosolic phospholipase A(2) activation. J Allergy Clin Immunol 2005; 116: 537-543.

11. Castro-Giner F, Kogevinas M, Imboden M, de Cid R, Jarvis D, Machler M, et al. Joint effect of obesity and TNFA variability on asthma: two international cohort studies. Eur Respir J 2009; 33: 1003-1009.

12. Khaodhiar L, Ling PR, Blackburn GL, Bistrian BR. Serum levels of interleukin-6 and C-reactive protein correlate with body mass index across the broad range of obesity. JPEN J Parenter Enteral Nutr 2004; 28: 410-415.

13. Tillie-Leblond I, Pugin J, Marquette $\mathrm{CH}$, Lamblin C, Saulnier F, Brichet A, et al. Balance between proinflammatory cytokines and their inhibitors in bronchial lavage from patients with status asthmaticus. Am J Respir Crit Care Med 1999; 159: 487-494.

14. Shore SA, Schwartzman IN, Mellema MS, Flynt L, Imrich A, Johnston RA. Effect of leptin on allergic airway responses in mice. J Allergy Clin Immunol 2005; 115:103-109.

15. Shore SA, Terry RD, Flynt L, Xu A, Hug C. Adiponectin attenuates allergen-induced airway inflammation and hyperresponsiveness in mice. J Allergy Clin Immunol 2006; 118: 389-395.

16. Kattan M, Kumar R, Bloomberg GR, Mitchell HE, Calatroni A, Gergen PJ, et al. Asthma control, adiposity, and adipokines among innercity adolescents. J Allergy Clin Immunol 2010; 125: 584-592.

17. Schaub B, Von Mutius E. Obesity and asthma, what are the links?. Curr Opin Allergy Clin Immunol 2005; 5: 185-193.

18. Lucas S, Platts-Mills T. Physical activity and exercise in asthma: relevance to etiology and treatment. J Asthma Allergy Clin Immunol 2005; 115 (5): 928-934.

19. Eneli IU, Skybo T, Camargo CA. Weight loss and asthma: a systematic review. Thorax 2008; 63 (8): 671-676.

20. Dixon A. Pathophysiological Changes in Asthma Induced by Weight Loss. Proc. Am. Thorac. Soc.; 2009: 6.

21. Expert Panel Report 3 (EPR-3): guidelines for the diagnosis and management of asthmasummary report 2007. J Allergy Clin Immunol 2007; 120 (suppl): S94-S138.
22. Butte NF, Ellis KJ. Comment on "Obesity and the environment: where do we go from here?". Science 2008; 301: 598.

23. Ramos E, Xu Y, Romanova I et al. Is obesity an inflammatory disease?. Surgery 2003; 134 (2): 329-335.

24. Shaaban R, Leynart B, Soussan D, et al. Physical activity and bronchial hyperresponsiveness: European community health survey. Thorax 2007; 62: 403-410.

25. Beuther D, Weiss S, Sutherland R. Obesity and asthma. Am J Respir Crit Care 2006; 174 (2):112120.

26. Eriksson M, Johnson O, Boman K, Hallmans G, Hellsten G, Nilsson TK, et al. Improved fibrinolytic activity during exercise may be an effect of the adipocyte-derived hormones leptin and adiponectin. Thromb Res 2008; 122 (5): 701708.

27. Fatouros IG, Tournis S, Leontsini D, Jamurtas AZ, Sxina M, Thomakos P, et al. Leptin and adiponectin responses in overweight inactive elderly following resistance training and detraining are intensity related. J Clin Endocrinol Metab 2005; 90 (11): 5970-5977.

28. Johnson JB, et al. Alternate day calorie restriction improves clinical findings and reduces markers of oxidative stress and inflammation in overweight adults with moderate asthma. Free Radic. Biol. Med. 2007; 42 (5): 665-674.

29. Gallistatl S, Sudi K, Aigner R, Borkenstein M. Changes in serum interleukin- 6 concentrations in obese children and adolescents during a weight reduction program. Int J Obes 2001; 25: 1640 1643.

30. Lim S, Choi SH, Jeong IK, Kim JH, Moon MK, Park KS, et al. Insulin-sensitizing effects of exercise on adiponectin and retinol-binding protein- 4 concentrations in young and middleaged women. J Clin Endocrinol Metab 2008; 93 (6): 2263-2268.

31. Kondo T, Kobayashi I, Murakami M. Effect of exercise on circulating adipokine levels in obese young women. Endocr J 2006; 53 (2): 189_ 195.

32. Bruun JM, Helge JW, Richelsen B, Stallknecht B. Diet and exercise reduce low-grade inflammation and macrophage infiltration in adipose tissue but not in skeletal muscle in severely obese subjects. Am J Physiol Endocrinol Metab 2006; 290(5):E961-7. 
33. Esposito K, Pontillo A, Di C et al. Effect of weight loss and lifestyle changes on vascular inflammatory markers in obese women: a randomized trial. JAMA 2003; 289 /14:1799_ 1804.

34. Reinher T, Roth C, Alexy U, Kersting M, Kiess W, Andler W. Leptin levels before and after reduction of overweight due to a low-fat high- carbohydrate diet in obese children and adolescents. Int J Obes 2005; 29: 362-368.

35. Kelly A, Steinberger J, Olson T, Dengel D. In the absence of weight loss, exercise training does not improve adipokines or oxidative stress in overweight children. Metabolism 2007; 56 (7): 1005-1059. 